\title{
Psychological Distress in Patients with Pectus Excavatum as an Indication for Therapy
}

\author{
Susanne Habelt ${ }^{1}$, Stephanie Korn ${ }^{2 *}$, Angelika Berger ${ }^{3}$, Jozef Bielek ${ }^{1}$ \\ ${ }^{1}$ Department of Pediatric Surgery, University Childrens' Hospital Basle, Basle, Switzerland; ${ }^{2}$ Pulmonary Department, Mainz Univer- \\ sity Hospital, Mainz, Germany; ${ }^{3}$ Child and Adolescent Psychitric Department Baselland, Baselland, Switzerland. \\ Email: "Stephanie.Korn@unimedizin-mainz.de
}

Received February $6^{\text {th }}, 2011$; revised April 11 ${ }^{\text {th }}, 2011$; accepted April 22 ${ }^{\text {nd }}, 2011$.

\begin{abstract}
Background: Adolescents with pectus excavatum (PE) are often affected by their body shape. The aim of our approach was to quantify the patients' individual psychological distress and to create a psychological indication for treatment. Methods: 10 adolescents (8 male, median age 16 years, interquartile range 15 - 17 yrs.) with PE were examined at our psychological department. Using standardized psychological tests, projective tests and interviews psychologists validated the patients' individual psychological status. All patients were offered psychological therapy and correction of the deformity. In addition, the children were followed-up by a telephone questionnaire (median follow-up after starting therapy 12.8 months $(5.9$ - 18.0). Results: No patient had a relevant physiological limitation. The median follow-up since presentation to our psychologists was 15.0 months $(9.1$ - 20.6). 8 patients (5 were operated, 2 used the vacuum bell, 1 will undergo surgery) had distinct psychological limitations especially concerning the dimensions attractiveness, self-esteem and somatisation. They demonstrated increased insecurity, anxiety and denegation of their body. Since all patients were within puberty the psychological distress due to the PE has to be interpreted as disadvantageous for their further development. 7 patients completed the follow-up questionnaire and reached a median score of $80.8 \%$ (76.4\% 86.8\%), which indicates a good improvement in all patients. Conclusions: We conclude that the psychological indication for treatment is justified, since our results support this indication.
\end{abstract}

Keywords: Chest Wall Deformity, Pectus Excavatum, Psychological Distress, Surgery, Vacuum Bell

\section{Introduction}

Pectus excavatum (PE), or funnel chest, is the most common congenital chest wall deformity occurring in approximately one per thousand children, with a $4: 1$ male predominance [1]. Various surgical [2,3] and nonsurgical $[4,5]$ techniques are described for repair of PE.

Although many objective criteria for evaluating chest wall deformities and determining indications have been reported such as the Haller Index [6,7], few studies have examined the psychological problems associated with PE [8].

In many cases, the degree of pectus deformity does not warrant repair due to physiological limitations. Therefore, treatment is often performed on a cosmetic basis. This creates problems since therapy for cosmetic reasons is usually not covered by insurance.

It is well known that children with PE are affected by their body image, that they often experience embarrassment, have low self-esteem and feelings of stigma [9].
These psychological criteria influence the patient's life deeply. In the past years, several studies examined the quality of life of these children, which demonstrated that the adolescents improve after therapy [10,11]. Nevertheless, until now repair of PE a psychological basis without any physiological restrictions has been controversial $[8,11]$. It is now recommended to extend the indication for therapy to psychological factors [12].

With this as background the aim of our evaluation was to perform an extended psychological status in order to establish a psychological indication for treatment. Therefore, psychologists quantified psychological characteris- tics of adolescents suffering from PE, who had no phy- siological limitations.

\section{Materials and Methods}

10 consecutive teenagers $(8$ male, median age at time of psychological assessment 16 years (interquartile range 15 - 17 yrs.)) with PE were examined at our psychological 
department in Basle, Switzerland as part of our routine assessment prior to treatment. Our assessment includes lung function tests, echocardiographic examinations and computed tomographies of the chest. Sternum-vertebral ratio indices are not obtained on a regular basis. In accordance with Krasopoulos et al. [10] we remain unaware of the significance of such indices as a parameter for the individual distress.

Using special standardized psychological tests and projective tests in combination with interviews with the adolescents and their parents' psychologists assessed the patients' individual psychological strain.

All children were offered surgical or non-surgical treatment. The choice of therapy depended on the patient's personal preference. Surgical correction was done using the Nuss procedur [3]. In the case of non-surgical therapy the patients used the vacuum chest wall lifter first described by Schier et al. [5].

All children were followed-up at our outpatient clinic. In addition, using a telephone questionnaire they were asked about their social and psychological status and their individual satisfaction after therapy.

\subsection{Tests}

For psychological examination several specific psychological tests were used. All tests were assessed by Hogrefe, a German test agency (Göttingen, Germany).

Body appraisal inventory ( $F B e K)$ :

The subjective body-experience is examined with a combination of body and complaint centered questionnaires. It consists of 4 scales: insecurity/worrying, concern of physical appearance, attractiveness/self-confidence, and negative feelings about physical-sexual functioning.

Body image inventory (FBK-20):

This test consists of 2 scales: negative body appraisal as well as vitality and body-dynamic.

Manual for the self-esteem for children and youngsters $(A L S)$ :

The manual for the self-esteem for children and adolescents is a self-reporting inventory for classifying children's perception of themselves in various specific domains of life: school, leisure time, family or children's home. These scales were constructed on the assumption that an instrument with separate information of one's self-esteem in different domains would provide a more differentiated picture than those instruments providing only a single self-concept score.

Youth Self Report (YSR) and Child Behavior Checklist (CBCL):

In the YSR the adolescents classify each position themselves and rate for how true each item is. The CBCL is rated by the parents and allows to cross check values given by the children. Both tests use a three-point response scale. The YSR and CBCL scoring profiles provide scores for two competence scales (activity scale: measuring the child's participation in hobbies, games, sports, jobs, chores, friendship; social scale: measuring withdrawn, somatic complaints, anxiety and depression, social problems, thought problems, attention problems, aggressive behaviour, and delinquent behaviours), for a total competence scale and for the eight syndrome scales that form three sub-dimensions. The subdimensions are referred to as 'internalizing,' 'externalizing' and 'neither internalizing nor externalizing'.

Overall behavioural and emotional functioning are measured by the total problem scale. In addition, the CBCL consists of a third scale regarding school achievement.

\section{Symptom Checklist-90-R (SCL-90-R):}

The Symptom Checklist-90-R is used as an instrument to evaluate a broad range of psychological problems and symptoms of psychopathology. The test describes 9 primary symptom dimensions (somatisation, obsessivecompulsiveness, interpersonal sensitivity, depression, anxiety, hostility, phobic anxiety, paranoid ideation, psychoticism) and is designed to provide an overview of a patient's symptoms and their intensity at a specific point of time. In addition, the test provides three global indices: Global Severity Index (GSI): designed to measure the overall psychological distress, it can be used as a summary of the test; Positive Symptom Distress Index (PSDI): designed to measure the intensity of symptoms and Positive Symptom Total (PST): reports the number of self-reported symptoms.

Follow-up questionnaire:

This questionnaire consisted of questions of the single step questionnaire by Krasopoulos et al. [10], of the Nuss-Questionnaire as published by Lawson et al. [13] and of questions chosen by a psychologist of our psychological department. The questionnaire consisted of 9 questions (Table 1) and the scoring ranges from 1 to 5 points per question $(1=$ much worse $(--), 2=$ worse $(-), 3$ $=$ about the same $(0), 4=$ better $(+), 5=$ much better $(++))$ resulting in a minimum score of 9 and a maximum score of 45. A total score of $>27$, accordingly $>60 \%$ means improvement, whereas $\leq 60 \%$ means no change or worsening.

\subsection{Statistical Analysis}

Scoring profiles of the psychological tests provide raw scores and percentiles. The interpretive reports are based on age-appropriate non-patient norm groups. Using the percentiles data description is primarily based on medians and quartiles (interquartile range) for continuous 
Table 1. Follow-up questionnaire.

\begin{tabular}{|c|c|c|c|c|c|c|}
\hline & & $\begin{array}{l}\text { Much worse } \\
(--)\end{array}$ & $\begin{array}{c}\text { Somewhat worse } \\
(-)\end{array}$ & $\begin{array}{l}\text { About the same } \\
(0)\end{array}$ & $\begin{array}{c}\text { Somewhat better } \\
(+)\end{array}$ & $\begin{array}{c}\text { Much better } \\
(++)\end{array}$ \\
\hline 1 & Overall feeling/satisfaction after therapy & 1 & 2 & 3 & 4 & 5 \\
\hline 2 & $\begin{array}{l}\text { Difficulties (sports without shirt, e.g. swimming, } \\
\text { subjective feeling of shortness of breath) after } \\
\text { therapy }\end{array}$ & 1 & 2 & 3 & 4 & 5 \\
\hline 3 & Health in general after therapy & 1 & 2 & 3 & 4 & 5 \\
\hline 4 & Exercise capacity after therapy & 1 & 2 & 3 & 4 & 5 \\
\hline 5 & $\begin{array}{l}\text { Satisfaction with overall appearance of the chest } \\
\text { after therapy }\end{array}$ & 1 & 2 & 3 & 4 & 5 \\
\hline 6 & Impact to social life & 1 & 2 & 3 & 4 & 5 \\
\hline \multirow[t]{2}{*}{7} & Self-consciousness because of chest/self-esteem & 1 & 2 & 3 & 4 & 5 \\
\hline & & $\begin{array}{c}\text { Never } \\
(--)\end{array}$ & $\begin{array}{l}\text { No } \\
(-)\end{array}$ & $\begin{array}{l}\text { Neutral } \\
\quad(0)\end{array}$ & $\begin{array}{l}\text { Yes } \\
(+)\end{array}$ & $\begin{array}{l}\text { Absolutely } \\
\qquad(++)\end{array}$ \\
\hline 8 & Therapy was considered to be good for me & 1 & 2 & 3 & 4 & 5 \\
\hline 9 & $\begin{array}{l}\text { Going back, would you have the elected therapy } \\
\text { again? }\end{array}$ & 1 & 2 & 3 & 4 & 5 \\
\hline
\end{tabular}

endpoints and on frequencies for binary endpoints. Every psychological test was analyzed on the basis of its sub-dimensions, its global results and on its special criteria. In addition, all tests combined with the projective tests and the interviews were used to assess the individuals' psychological distress as a whole.

\section{Results}

Eight male and two female patients with a median age of 16 years (interquartile range 15 - 17 years) were seen at our Department of Pediatric Surgery for evaluation of their pectus excavatum (PE). Prior to treatment they were examined according to our routine assessment program. None of the patients had a physiological limitation, echocardiographic examination was defined as normal in all patients, lung function tests were normal in 8 patients. One patient demonstrated a limited restrictive defect and one patient was known to have asthma (Table 2). Additionally, the patients were assessed to our psychological department and a psychological status was obtained. The median follow-up since presenting at the psychologist is 15.0 months (interquartile range 9.1 - 21.4 months); the psychological status was taken at the same time or within a few days after medical examination and at a median of 17.8 weeks (interquartile range 2.4 - 27.0 weeks) before

Table 2. Lung function tests preoperatively.

\begin{tabular}{lccc}
\hline & $n$ & $\begin{array}{c}\text { Median } \\
\text { (interquartile range) }\end{array}$ & $\begin{array}{c}\text { Minimum; } \\
\text { Maximum }\end{array}$ \\
\hline $\begin{array}{l}\text { Vital capacity } \\
\text { (\% predicted) }\end{array}$ & 10 & $84.1(77.7-91.6)$ & $69.0 ; 101.3$ \\
FEV1 (\% predicted) & 10 & $90.2(80.9-92.8)$ & $70.0 ; 99.4$ \\
Residual volume (\%) & 10 & $109.9(88.3-143.4)$ & $54.9 ; 192.0$ \\
Total lung capacity (\%) & 10 & $92.9(81.0-100.6)$ & $74.6 ; 108.6$ \\
\hline
\end{tabular}

Displayed are median scores, interquartile ranges, minimum and maximum of the lung function parameters. starting therapy.

The results of the single tests and their sub-dimensions are demonstrated in Table 3 . In addition, we specified how many patients were at risk in a sub-dimension and in the specific test. Overall, 8 patients had psychological limitations especially concerning the dimensions attractiveness, self-esteem and somatisation. Eight children shied away from presenting their body for instance when going swimming or doing sports. This resulted in increased insecurity, anxiety and denegation of the own body. Four patients complained about breathlessness although they did not have any pulmonary limitation. All patients were offered surgical treatment, since 2005 surgical or non-surgical treatment. Of the 8 patients with psychological distress 6 elected surgery (one will undergo surgery in two months), the remaining 2 decided to use the vacuum chest wall lifter. Of the 2 patients without psychological limitation one did not desire any therapy and the other one elected therapy with the vacuum bell for a better cosmetic result.

All patients were followed up at our outpatient clinic and were asked to complete the telephone questionnaire despite the one who did not desire therapy and the one who has not undergone surgery by now. 7 patients (of 8 interview patients) completed the questionnaire with a median follow-up of 13 months (interquartile range 6 18 months) after starting therapy; one patient could not be asked due to being in Africa for one year. The teenagers reached a median score of $80.8 \%$ (interquartile range $76.4 \%-86.8 \%$ ). Since a total score of $>60 \%$ was defined as improvement, all patients demonstrated good improvement after therapy and stated satisfaction with the overall result of the treatment. All children improved concerning earlier difficulties, attractiveness, self-esteem and social life and recommended their type of therapy. 
Table 3. Results of the different psychological tests including their subdimensions.

\begin{tabular}{|c|c|c|c|c|}
\hline & $n$ & $\begin{array}{c}\text { Median } \\
\text { (interquartile range) }\end{array}$ & Min.; Max. & at risk $(n)$ \\
\hline \multicolumn{5}{|l|}{ Body appraisal inventory (FBeK) } \\
\hline $\begin{array}{l}\text { Insecurity/worrying } \\
\text { (scores above } 84 \% \text { are classified as at risk) }\end{array}$ & 9 & $49.0(18.0-86.5)$ & $6.0 ; 97.0$ & 2 \\
\hline $\begin{array}{l}\text { Concern with physical appearance } \\
\text { (scores below } 16 \% \text { are classified as at risk) }\end{array}$ & 9 & $57.0(25.0-62.5)$ & $15.0 ; 98.0$ & 1 \\
\hline $\begin{array}{l}\text { Attractiveness/self-confidence } \\
\text { (scores below } 16 \% \text { are classified as at risk) }\end{array}$ & 9 & $14.0(1.5-60.0)$ & $1.0 ; 100.0$ & 5 \\
\hline $\begin{array}{l}\text { Physical-sexual functioning } \\
\text { (scores above } 84 \text { are classified as at risk) }\end{array}$ & 7 & $65.0(22.0-69.0)$ & $22.0 ; 93.0$ & 1 \\
\hline Total & & & & 5 \\
\hline \multicolumn{5}{|l|}{ Body image inventory (FBK-20) } \\
\hline $\begin{array}{l}\text { Negative body appraisal } \\
\text { (scores above } 84 \% \text { are classified as at risk) }\end{array}$ & 9 & $60.0(8.0-87.5)$ & $1.0 ; 99.0$ & 4 \\
\hline $\begin{array}{l}\text { Vitality and body dynamic } \\
\text { (scores below } 16 \% \text { are classified as at risk) }\end{array}$ & 9 & $40.0(15.0-47.5)$ & $4.0 ; 90.0$ & 2 \\
\hline Total & & & & 6 \\
\hline \multicolumn{5}{|c|}{$\begin{array}{l}\text { Manual for the self-esteem for children and youngster (ALS) } \\
\text { (scores of } 11 \%-25 \% \text { are classified as at risk) }\end{array}$} \\
\hline School & 8 & 0 & & 1 \\
\hline Leisure time & 8 & 1 & & 1 \\
\hline Family/children's home & 8 & 1 & & 1 \\
\hline Total & & & & 3 \\
\hline \multicolumn{5}{|l|}{$\begin{array}{l}\text { Youth Self Report (YSR) } \\
\text { (scores above } 98 \% \text { are clas }\end{array}$} \\
\hline Withdrawn & 5 & $84.0(50.0-88.0)$ & $50.0 ; 92.0$ & 0 \\
\hline Somatic complaints & 5 & $92.0(58.5-98.3)$ & $50.0 ; 98.5$ & 2 \\
\hline Anxiety/depression & 5 & $50.0(50.0-84.2)$ & $50.0 ; 98.3$ & 1 \\
\hline Social problems & 5 & $50.0(50.0-65.0)$ & $50.0 ; 80.0$ & 0 \\
\hline Thought problems & 5 & $50.0(50.0-83.0)$ & $50.0 ; 93.0$ & 0 \\
\hline Aggressive behaviour & 5 & $50.0(50.0-85.0)$ & $50.0 ; 86.0$ & 0 \\
\hline Activity scale & 5 & $69.0(63.5-69.0)$ & $58.0 ; 69.0$ & 0 \\
\hline Social scale & 5 & $69.0(57.0-69.0)$ & $46.0 ; 69.0$ & 0 \\
\hline Total & & & & 2 \\
\hline \multicolumn{5}{|l|}{$\begin{array}{l}\text { Child Behaviour Checklist (CBCL) } \\
\text { (scores above } 98 \% \text { are classified as at }\end{array}$} \\
\hline Withdrawn & 4 & $59.5(50.0-81.8)$ & $50.0 ; 86.0$ & 0 \\
\hline Somatic complaints & 4 & $68.0(54.5-68.8)$ & $50.0 ; 69.0$ & 0 \\
\hline Anxiety/depression & 4 & $61.0(50.0-86.3)$ & $50.0 ; 91.0$ & 0 \\
\hline Social problems & 4 & $68.0(54.5-68.8)$ & $50.0 ; 69.0$ & 0 \\
\hline Thought problems & 4 & $55.0(50.0-86.3)$ & $50.0 ; 95.0$ & 0 \\
\hline Attention problems & 4 & $60.0(52.5-81.0)$ & $50.0 ; 88.0$ & 0 \\
\hline Delinquent behaviours & 4 & $50.0(50.0-57.5)$ & $50.0 ; 60.0$ & 0 \\
\hline Aggressive behaviour & 4 & $59.0(52.0-66.8)$ & $50.0 ; 69.0$ & 0 \\
\hline Activity scale & 4 & $69.0(45.0-69.0)$ & $37.0 ; 69.0$ & 0 \\
\hline Social scale & 4 & $69.0(36.0-69.0)$ & $25.0 ; 69.0$ & 0 \\
\hline School scale & 4 & $60.5(49.8-69.0)$ & $49.0 ; 69.0$ & 0 \\
\hline Total & & & & $\mathbf{0}$ \\
\hline \multicolumn{5}{|c|}{$\begin{array}{l}\text { Symptom Checklist } \mathbf{9 0 - R} \text { (SCL-90-R) } \\
\text { (scores above } 84 \% \text { are classified as at risk indicating psychological problems) }\end{array}$} \\
\hline Somatisation & 10 & $96.0(6.0-96.9)$ & $3.0 ; 99.0$ & 5 \\
\hline Obsessive-compulsive & 10 & $60.5(12.8-98.1)$ & $5.0 ; 99.0$ & 5 \\
\hline Interpersonal sensitivity & 10 & $52.5(5.0-94.3)$ & $5.0 ; 100.0$ & 4 \\
\hline Depression & 10 & $44.0(7.0-98.1)$ & $7.0 ; 100.0$ & 4 \\
\hline Anxiety & 10 & $61.0(7.0-98.6)$ & $7.0 ; 100.0$ & 4 \\
\hline Hostility & 10 & $25.5(20.8-93.3)$ & $7.0 ; 94.0$ & 4 \\
\hline
\end{tabular}




\begin{tabular}{lcccc}
\hline Phobic anxiety & 10 & $73.5(55.8-94.8)$ & $22.0 ; 100.0$ & 4 \\
Paranoid ideation & 10 & $65.0(11.0-98.1)$ & $11.0 ; 100.0$ & 4 \\
Psychoticism & 10 & $43.5(11.0-94.4)$ & $11.0 ; 99.0$ & 3 \\
GSI & 10 & $57.5(10.5-99.0)$ & $2.0 ; 100.0$ & 4 \\
PSDI & 10 & $56.0(9.0-98.0)$ & $9.0 ; 99.0$ & 4 \\
PST & 10 & $54.0(2.8-96.5)$ & $2.0 ; 99.0$ & 4 \\
Total & & & & $\mathbf{6}$ \\
& & & & $\mathbf{8}$ \\
Total & 10 & & & \\
\hline
\end{tabular}

Displayed are median scores, interquartile ranges, minimum and maximum of the several psychological tests with sub-dimensions reached by the patients. In addition, number of patients with at risk findings, indicating psychological problems are shown. Total: number of patients in whom the test was classified as at risk (in one or more sub-dimensions).

\section{Discussion}

Today, the indications for treatment of PE are mainly based on physiological symptoms or cosmetic factors [12]. Indications based on psychological or psycho-social stress are frequently discussed $[8,12]$ and are part of questionnaires that assess the patients' preoperative condition $[8,10]$.

Therefore, we picked-up the suggestion made by Suita et al. [12] and Ohno et al. [8] to extend the indications for treatment, especially for surgery, in regard to the patients' individual psychological stress.

We described the way of establishing a psychological indication for therapy of PE. To date, there has been increasing research on the psychological aspects of pectus deformities or other disfiguring conditions in general and medical procedures used to correct them $[14,15]$. The psychological importance of the body image including the notion that medical treatment can improve quality of life has been described in some detail and there are questionnaires to assess the preoperative status of children with PE $[10,11]$. Nevertheless, to perform an accurate and extensive psychological assessment it is important to identify the children's individual psychological strain including various dimensions.

It is well known that patients with PE often experience embarrassment and shame over the perceived differences in their physical appearance and that this can lead to lowered self-concept, feelings of inferiority, depression, shyness and social anxiety [16]. This was found in the majority $(8 / 10)$ of our children. The results of our examination demonstrated that the handicaps of PE influence all areas of life. Defensive camouflaging with poor posture and folded arms, restrictions in lifestyle including avoidance of swimming, sports, hugging and intimate relationships were described by our patients. Particularly, since all patients hit puberty the psychological strain due to the PE has to be interpreted as disadvantageous for their further development.

After psychological assessment our patients were offered surgical and non-surgical treatment. All adolescents with psychological problems decided to be treated. One patient wanted to be treated with the vacuum bell some time after presentation at the psychological department due to a better cosmetic result although he did not feel limited. According to the study by Ohno et al. [8] not all distressed patients wanted surgery, 2 patients wanted to try therapy with the vacuum bell, which is understandable since it is a less invasive therapeutic option producing increased interest with the patients during the last year [5].

It is well known that medical therapy improves quality of life as described by Roberts et al. using the QOL outlined by Keith and Shacklock [11]. Their results indicate an improvement in each of the four areas satisfaction, social belonging, well-being and empowerment/control. In accordance, Lawson et al. created a Pectus Excavatum Evaluation Questionnaire and demonstrated a positive impact on the well-being of children after surgical repair [13]. Since there are several studies which confirm improvement after correction of the chest deformity we only used a short questionnaire to ask the patients about their individual improvement after therapy. Therefore, we modified the questionnaire of Krasopoulos et al. [10] and Lawson et al. [13] to especially evaluate the factors attractiveness, body image, social improvement and satisfaction in general. Nearly all children reported improved endurance and participation in physical education activities after therapy. We reason this with the better quality of life and better satisfaction with their physical appearance, not due to any physiological improvement since the children did not have any physical limitation prior to treatment.

A limitation of our study is the small number of patients. All consecutive patients with pectus excavatum were included to avoid selection bias. However, it cannot be excluded that the results of the present study may slightly change if more patients over a longer study period would be included. However, from previous experience we strongly feel that the results of the present study are representative for a large referral center in a developed county such as Switzerland. 
Suita et al. comment that the precise indications for surgical repair of PE is still open [12]. In our opinion, the definition of the indication should depend on physical and psychological characteristics in each case. In the course of this, not only somatic data, but also psychological factors should be considered. We think psychological aspects should not only be taken into consideration but the children with PE should be presented to a psychologist. We recommend including psychological distress to the list of indications for therapy as an independent factor. Nevertheless, further studies with more patients will be needed to underline our findings.

\section{Conclusions}

In summary, most children with PE suffered from psychological strain and all patients improved after therapy. We therefore recommend working together with psychologists to extend the indications for therapy of PE to psychological problems. The individual psychological limitation can be assessed by psychologists using special medical tests, projective tests and interviews with the patients and their parents. Thus, it is possible to gain information in several dimensions especially attractiveness, self-esteem and social life which affect the patients in all areas of life. We conclude that the psychological indication for treatment is justified, since our results support this indication.

\section{REFERENCES}

[1] K. A. Molik, S. A. Engum, F. J. Rescorla, K. W. West, L. R. Scherer and J. L. Grosfeld, "Pectus Excavatum Repair: Experience with Standard and Minimal Invasive Techinques," Journal of Pediatric Surgery, Vol. 36, No. 2, 2001, pp. 324-328. doi:10.1053/ipsu.2001.20707

[2] E. W. Fonkalsrud, "Current Management of Pectus Excavatum," World Journal of Surgery, Vol. 27, No. 5, 2003, pp. 502-508. doi:10.1007/s00268-003-7025-5

[3] D. Nuss, R. E. Kelly Jr., D. P. Croitoru and M. E. Katz, "A 10-Year Review of a Minimally Invasive Technique for the Correction of Pectus Excavatum," Journal of Pediatric Surgery, Vol. 33, No. 4, 1998, pp. 545-552. doi:10.1016/S0022-3468(98)90314-1

[4] F. M. Haecker and J. Mayr, "The Vacuum Bell for Treatment of Pectus Excavatum: An Alternative to Surgical Correction?" European Journal of Cardio-Thoracic Surgery, Vol. 29, No. 4, 2006, pp. 557-561. doi:10.1016/j.ejcts.2006.01.025

[5] F. Schier, M. Bahr and E. Klobe, "The Vacuum Chest Wall Lifter: An Innovative, Nonsurgical Addition to the Management of Pectus Excavatum," Journal of Pediatric Surgery, Vol. 40, No. 3, 2005, pp. 496-500. doi:10.1016/i.jpedsurg.2004.11.033

[6] S. W. Daunt, J. H. Cohen and S. F. Miller, "Age-Related Normal Ranges for the Haller Index in Children," Pediatric Radiology, Vol. 34, No. 4, 2004, pp. 326-330. doi:10.1007/s00247-003-1116-1

[7] J. A. Haller Jr., S. S. Kramer and S. A. Lietman, "Use of CT Scans in Selection of Patients for Pectus Excavatum Surgery: A Preliminary Report," Journal of Pediatric Surgery, Vol. 22, No. 10, 1987, pp. 904-906. doi:10.1016/S0022-3468(87)80585-7

[8] K. Ohno, Y. Morotomi, M. Nakahira, S. Takeuchi, et al., "Indications for Surgical Repair of Funnel Chest Based on Indices of Chest Wall Deformity and Psychological State," Surgery Today, Vol. 33, No. 9, 2003, pp. 662-665. doi:10.1007/s00595-003-2575-6

[9] E. Einsiedel and A. Clausner, "Funnel Chest. Psychological and Psychosomatic Aspects in Children, Youngsters, and Young Adults," The Journal of Cardiovascular Surgery (Torino), Vol. 40, No. 5, 1999, pp. 733-736.

[10] G. Krasopoulos, M. Dusmet, G. Ladas and P. Goldstraw, "Nuss Procedure Improves the Quality of Life in Young Male Adults with Pectus Excavatum Deformity," The European Journal of Cardio-Thoracic Surgery, Vol. 29, No. 1, 2006, pp. 1-5. doi:10.1016/j.ejcts.2005.09.018

[11] J. Roberts, A. Hayashi, J. O. Anderson, J. M. Martin and L. L. Maxwell, "Quality of Life of Patients Who Have Undergone the Nuss Procedure for Pectus Excavatum: Preliminary Findings," Journal of Pediatric Surgery, Vol. 38, No. 5, 2003, pp. 779-783. doi:10.1016/jpsu.2003.50166

[12] S. Suita, T. Taguchi, K. Masumoto, M. Kubota and T. Kamimura, "Funnel Chest: Treatment Strategy and Follow-Up," Pediatric Surgery International, Vol. 17, No. 56, 2001, pp. 344-350. doi:10.1007/s003830000575

[13] M. L. Lawson, T. F. Cash, R. Akers, E. Vasser, B. Burke, M. Tabangin, et al., "A Pilot Study of the Impact of Surgical Repair on Disease-Specific Quality of Life among Patients with Pectus Excavatum," Journal of Pediatric Surgery, Vol. 38, No. 6, 2003, pp. 916-918. doi:10.1016/S0022-3468(03)00123-4

[14] G. Kent and S. Keohane, "Social Anxiety and Disfigurement: The Moderating Effects of Fear of Negative Evaluation and Past Experience," British Journal of Psychology, Vol. 40, No. Part 1, 2001, pp. 23-34.

[15] A. Thompson and G. Kent, "Adjusting to Disfigurement: Process Involved in Dealing with Being Visibly Different," Clinical Psychology Review, Vol. 21, No. 5, 2001, pp. 663-682. doi:10.1016/S0272-7358(00)00056-8

[16] S. W. Noles, T. F. Cash and B. A. Winstead, "Body Image, Physical Attractiveness, and Depression," Journal of Consulting and Clinical Psychology, Vol. 53, 1985, pp. 88-94. doi:10.1037/0022-006X.53.1.88 